\title{
PERFIL E PREFERÊNCIAS DO CONSUMIDOR DE PÊSSEGO (Prunus persica) EM DIFERENTES REGIÕES PRODUTORAS NO RIO GRANDE DO SUL ${ }^{1}$
}

\author{
RENATO TREVISAN², CLAUSE FÁTIMA DE BRUM PIANA ${ }^{3}$, ROSA DE OLIVEIRA TREPTOW ${ }^{4}$, \\ EMERSON DIAS GONÇALVES ${ }^{5}$, LUIS EDUARDO CORRÊA ANTUNES ${ }^{6}$
}

RESUMO- Entender a qualidade percebida pelo consumidor é fundamental para aquele que deseja não apenas produzir frutas, mas também comercializá-las. Além disso, conhecer o consumidor e seus hábitos contribui no adequado planejamento de ações nos diversos segmentos da cadeia produtiva. Procurou-se verificar o perfil e a preferência dos consumidores de pêssego in natura, em três cidades do Rio Grande do Sul. A partir das respostas ao questionário aplicado, traçou-se seu perfil quanto as suas exigências relativas ao hábito de compra e da qualidade da fruta. Utilizou-se a estatística de Qui-quadrado para verificar a ocorrência de independência entre as variáveis obtidas por meio das respostas dos consumidores em uma amostra de 430 entrevistados entre as três cidades. Constatou-se que o perfil e a preferência dos consumidores de pêssego são distintos nas três cidades pesquisadas quanto ao local de compra e a preferência pela cor da polpa, porém a coloração amarelo-avermelhada da epiderme, o consumo semanal e o sabor são atributos semelhantes para os consumidores nas três cidades.

Termos para indexação: Prunus persica; padrão de qualidade; teste de preferência; mercado.

\section{PROFILE AND PREFERENCES OF PEACH (Prunus persica) CONSUMERS IN DIFFERENT REGIONS OF RIO GRANDE DO SUL}

\begin{abstract}
Understanding the quality perceived by the consumer is important for those who want not only produce food but also market it. Furthermore, knowing the consumer and their habits helps planning appropriate actions in the various segments of the production chain. Thus, it was verified the profile and the preferences of consumers in natura of peach in three major cities of Rio Grande do Sul. Responses to the questionnaire applied, drew up its profile as their requirements concerning to the habit of buying and the quality of fruit. It was used the chi-square statistic to verify the occurrence of independence between variables obtained through the responses of consumers in a sample of 430 interviewees among the three cities. It was verified that the profile and the preferences of consumers of peach are different in the three cities surveyed as to the place of purchase and the preference of the color of the flesh, however, the yellow-reddish epidermis, the weekly consumption and the flavor, are similar attributes for consumers in the three cities. Index terms: Prunus persica; quality standards; preference test, market.
\end{abstract}

\section{INTRODUÇÃO}

Entender a qualidade percebida pelo consumidor é fundamental quando se pretende não apenas produzir alimentos, mas também comercializá-los. Identificar os fatores de qualidade que são relevantes ao consumidor e sua relação com os parâmetros físicos e químicos do produto é fundamental. Além disso, conhecer os hábitos e características da população consumidora contribui positivamente para um adequado planejamento de ações nos diversos segmentos da cadeia produtiva.
A aceitação do pêssego pelos consumidores deve-se, principalmente, às características sensoriais, notadamente o sabor. Porém, o consumo de pêssegos per capita no RS é baixo (300g hab ano-1 em 2005), embora, no ano de 2000, a região de Porto Alegre atingiu o consumo de $1 \mathrm{~kg}$ hab ano-1 (Marodin \& Sartori, 2000). Mesmo assim, apesar do consumo relativamente baixo, cresceu o grau de exigência dos consumidores em relação à qualidade das frutas. Atualmente, a grande mudança no agronegócio não está somente na quantidade produzida, mas também na atitude e no comportamento do consumidor e suas implicações. Embora exista um grande número de

\footnotetext{
${ }^{1}$ (Trabalho 026-09). Recebido em: 10-01-2009. Aceito para publicação em: 17-08-2009.

${ }^{2} \mathrm{Eng}^{\circ} \mathrm{Agr}^{\circ}$. Dr. Prof. CAFW/UFSM, Caixa Postal 54 CEP 98400-000 Frederico Westphalen-RS. renato.trevisan@smail.ufsm.br ${ }^{3}$ Bióloga, MsC. Prof., UFPel, Caixa Postal 354, CEP 96010-900, Pelotas-RS. clausepiana@yahoo.com.br

${ }^{4}$ Economista Doméstica, MsC. Embrapa Clima Temperado, Caixa Postal 403, CEP 96001-970 Pelotas-RS. rotreptow@hotmail.com ${ }^{5} \mathrm{Eng}^{\circ} \mathrm{Agr}^{\circ}$. Dr. Pesquisador, EPAMIG, Fazenda experimental Maria da Fé-MG. emerson@epamig.br

${ }^{6} \mathrm{Eng}^{\circ} \mathrm{Agr}{ }^{\circ}$. Dr. Pesquisador, Embrapa Clima Temperado, Caixa Postal 403, CEP 96001-970 Pelotas-RS. E-mail: antunes@cpact.embrapa.br
} 
cultivares de pessegueiros desenvolvidas e adaptadas às regiões do Brasil, o perfil e as preferências do consumidor desta fruta não são totalmente conhecidos.

Os programas de melhoramento genético de pessegueiro, além de atentarem para os problemas de cultivo da espécie, selecionando cultivares que apresentem alta produtividade, resistência a doenças e pragas e melhor adaptação, vêm buscando também atributos de qualidade exigidos pelo mercado, como aparência, sabor, aroma, textura, vida útil, entre outros.

Segundo Hooley et al. (2001), a identificação da necessidade dos consumidores implica a realização de pesquisas para descobrir primeiramente quem são, seguido do que lhe dá satisfação. A qualidade centrada no consumidor é a totalidade de aspectos e características de um produto que proporcione a satisfação de suas necessidades.

A qualidade dos produtos frescos é dada pela combinação de uma série de características, atributos e propriedades que lhes dão valor e que devem satisfazer às necessidades do consumidor. A aparência de uma fruta abrange diversos atributos sensoriais básicos, como: a cor, o brilho, a estrutura visual, a textura e o sabor percebido. Dentre esses aspectos visuais, o efeito da cor é o mais óbvio e bem estudado (Imram, 1999).

Para Castellari et al. (2006), a qualidade da fruta deve ser percebida, reconhecida e valorizada pelo consumidor. Entretanto, os critérios estabelecidos pelos consumidores na escolha de um produto são diferentes. Gonçalves (1998), ao identificar o perfil do consumidor de frutas frescas na cidade de Lavras, Minas Gerais, observou que a qualidade das frutas, representada pelos atributos aparência, textura, frescor e sabor, e o preço constituíram os critérios mais relevantes. Para os consumidores de banana de Cruz das Almas, Bahia, o sabor, a vida útil e a aparência foram considerados os atributos mais importantes no momento da escolha (Matsuura, et al., 2004). Consumidores de Satsuma Mandarins (Citrus unshiu) do Alabama, EUA, destacam a cor como atributo importante no momento da compra (Campbell et al., 2004). Segundo Crisosto et al. (2003), os consumidores americanos de cereja preferem a coloração da epiderme vermelho-escura brilhante e,no mínimo, $16 \%$ de sólidos solúveis. Toralles et al. (2006) constataram que consumidores preferem purês de pêssego de coloração amarela e doce.

Diante do exposto, a ligação consumidor, varejista e produtor está cada vez mais dependente. O consumidor, pelo estilo de vida moderno, revela mudanças no hábito alimentar em consequência do tempo. O varejista quer oferecer produtos de qua- lidade, e o produtor, para manter-se no mercado, tem de produzir a custos mais competitivos e com qualidade. Nesta ligação, cada um desempenha seu papel, entretanto identificar e entender as exigências do consumidor é fundamental, e pode ser realizada através de dados coletados diretamente com os consumidores. Segundo Mattar (1999), a forma tradicional para coleta de dados primários (dados que nunca foram coletados, tabulados e analisados) é através da comunicação direta com o detentor dos dados, sendo o dado obtido pela declaração do próprio respondente, o que caracteriza o uso de entrevistas e questionários. Brumfield et al. (1993) e Wilkins et al. (2002) também utilizaram questionários como meio de coletar informações junto aos consumidores, indicando que esta metodologia representa facilidade e rapidez na obtenção dos dados.

O objetivo do trabalho foi traçar o perfil e a preferência do consumidor de pêssegos in natura, em três cidades do Rio Grande do Sul, considerando atributos de qualidade no momento da compra.

\section{MATERIAL E MÉTODOS}

Esta pesquisa foi realizada nas cidades de Porto Alegre, Pelotas e Santa'Ana do Livramento, no Estado do Rio Grande do Sul, no período de outubro de 2004 a fevereiro de 2005, com consumidores de pêssego.

No presente trabalho, a coleta de dados, nas três cidades, baseou-se numa pesquisa exploratória com algumas adaptações. Foram entrevistados 130 (centro e trinta) consumidores de pêssegos em Porto Alegre; 150 (cento e cinquenta) em Pelotas e 150 (cento e cinquenta) em Sant'Ana do Livramento. O questionário deu-se de forma individual, abordando os consumidores em ruas, praças e supermercados, não privilegiando nenhum grupo de consumidores, tanto pelo aspecto socioeconômico como racial.

O questionário continha treze perguntas para a determinação do perfil dos consumidores, destacando-se: (1) dados pessoais: sexo, faixa etária, escolaridade e profissão; (2) local de compra: armazém, feira livre, supermercados ou outros; (3) motivo da compra: alimento nutritivo, saudável, saboroso ou preço; (4) frequência de consumo: uma vez ao dia, de uma a duas vezes na semana, de 3 a 5 vezes na semana ou três vezes ao mês; (5) conhece as cultivares; (6) tamanho: pequeno CAT I: $>57 \mathrm{~mm}$, médio CAT II: 47 - 57 mm ou grande CAT III: 44 - $47 \mathrm{~mm}$; (7) firmeza de polpa: tenra, macia, dura ou crocante(Queiroz e Treptow 2006) ; (8) suculência: sem, pouco, regular ou muito suco; (Queiroz e Treptow 2006); (9) sabor: suave, regular ou intenso 
(Queiroz e Treptow 2006); (10) cor da polpa: creme, branca, amarela ou amarela intensa; (Queiroz e Treptow 2006) (11) cor da epiderme: amarelo-esverdeada, amarela, amarelo-avermelhada, laranja ou vermelha; (Queiroz e Treptow 2006); (12) doçura: muito doce, doce, doce-ácida, ácida ou muito ácida; (Queiroz e Treptow 2006); (13) atributo mais importante da fruta: cor da epiderme e polpa, tamanho, ausência de defeitos, firmeza, aroma ou outros (Queiroz e Treptow 2006).

Realizou-se uma análise gráfica e utilizou-se a estatística de qui-quadrado (SAS Institute, 1989) para verificar a ocorrência de independência entre as variáveis, a partir de uma amostra de 430 consumidores. Valores de probabilidade encontrados menores de 0,05 indicaram que o teste foi significativo, e as variáveis, independentes.

\section{RESULTADOS E DISCUSSÃO}

Os resultados revelaram que vários atributos pesquisados estão associados com a cidade (Tabela 1) e o sexo (Tabela 2) do consumidor. As frequências de diferentes ocupações, faixas etárias e níveis de escolaridade variam de uma cidade para outra. Os fatores socioeconômicos sexo e profissão também apresentam associação significativa entre si, em Sant'Ana do Livramento e Pelotas. Quanto aos hábitos dos consumidores, verificou-se que a motivação, a frequência, o local da compra e a identificação da cultivar também dependem do sexo e da cidade. Da mesma forma, a escolha de alguns caracteres de qualidade da fruta (cor da polpa, cor da epiderme, firmeza, tamanho, suculência são os atributos mais importante da fruta) varia com a cidade e a cor da polpa e tamanho, com o sexo do consumidor, conforme dados apresentados nas Tabelas e Figuras 1 e 2.

Nos três municípios pesquisados, o número de consumidores do sexo feminino foi maior que do sexo masculino: 63\%, em Pelotas, 52\% em Sant'Ana do Livramento e 62\% em Porto Alegre, indicando que a mulher ainda é a maior responsável pela compra de frutas na família. A faixa etária entre os consumidores variou significativamente entre as cidades. Em Pelotas e Porto Alegre, a maior frequência foi de 19 a 30 anos (34\% e 42\%, respectivamente), enquanto em Sant'Ana do Livramento foi de 41 a 60 anos (33\%). O grau de escolaridade predominante entre os consumidores de Pelotas e Sant'Ana do Livramento foi ensino médio (29\% e 43\%, respectivamente). Em Porto Alegre, a maior frequência foi de consumidores com curso superior completo (23\%).

Quanto à ocupação, houve diferença de frequências entre as cidades somente para os consumidores do sexo masculino. As ocupações predominantes, dentre as especificadas, foram: estudante (25\%) em Porto Alegre, funcionário (34\%) em Pelotas e estudante (22\%) e funcionário (22\%) em Sant'Ana do Livramento. Diferenças de frequências entre os sexos foram significativas para as cidades de Sant'Ana do Livramento e Pelotas. Na cidade de Pelotas, a ocupação mais frequente para consumidores do sexo feminino foi a de estudante (26\%), enquanto para os consumidores do sexo masculino foi a de funcionário (34\%); em Sant'Ana do Livramento, foi de dona de casa (31\%), para o sexo feminino, e de estudante e funcionário (22\% cada), para o sexo masculino.

Todos os atributos relativos aos hábitos dos consumidores variam de acordo com a cidade e o sexo do consumidor (Tabelas 1 e 2 ). O motivo da compra variou entre as cidades, mas as diferenças foram mais significativas para o sexo feminino (Tabela 2). Nas três cidades, a maioria das mulheres (61\% em Pelotas e Porto Alegre e 36\% em Sant'Ana do Livramento) e dos homens (64\% em Pelotas, 56\% em Porto Alegre, e 46\% em Sant'Ana do Livramento) compram pêssegos por considerá-lo uma fruta saborosa (Figura 1A). Gonçalves (1998) relatou que, além da qualidade das frutas, representada pelos atributos aparência, textura, frescor e sabor, o consumidor considera o preço um critério relevante no momento da compra. Entretanto, este critério foi inexpressivo entre os consumidores das três cidades pesquisadas.

Com relação ao local de compra, a pesquisa mostrou que, em Sant'Ana do Livramento e Pelotas, a feira livre foi o local mais frequente, enquanto em Porto Alegre os consumidores compram em supermercado (Figura 1B). Resultado semelhante ao de Porto Alegre foi observado em consumidores italianos, no ano de 2006, onde 34\% deles adquirem pêssegos em supermercado, e 25\% em comércio ambulante (Macchi, 2007).

A frequência do consumo de pêssegos variou entre as cidades, e apenas em Porto Alegre entre os sexos (Figura 1C e 1D). Em Pelotas (52\%) e Sant'Ana do Livramento (49\%), os consumidores compram pêssegos uma ou duas vezes na semana (Figura 1C). Em Porto Alegre, as mulheres compram com maior frequência (47\% uma a duas vezes por semana) do que os homens (57\% três vezes ao mês) (Figura 1D).

Embora a pesquisa tenha sido realizada no maior polo produtivo de pêssegos do Estado, a maioria dos consumidores ( $87 \%$ do total) desconhece as cultivares pelo nome. Pelotas é a cidade que tem 
maior conhecimento a respeito das cultivares (44\% dos homens e $11 \%$ das mulheres) (Figura 1E). Os consumidores que não conhecem as cultivares, identificam-nas somente pela cor da polpa, como cultivares de polpa amarela ou de polpa branca, ou molar.

O atributo na fruta que o consumidor considera mais importante no momento da compra variou de uma cidade para outra, mas não variou entre os sexos (Figura 2A). Em Pelotas (36\%) e Porto Alegre (32\%), os consumidores consideraram a ausência de defeitos o atributo mais relevante, enquanto os consumidores de Sant'Ana do Livramento (36\%) apontaram o tamanho da fruta (Figura 2A). Estes resultados assemelham-se aos de Lópes et al. (1998), que ao realizarem uma pesquisa com 455 consumidores de pêssego na Espanha, verificaram que a característica mais importante também é a ausência de defeitos (40\%), seguida pela cor da epiderme (30\%). Pio \& Ramos (2002) observaram que a qualidade geral e a aparência do produto foram os principais critérios utilizados pelos consumidores para efetuar a compra de frutas.

Philipsen et al. (1995) verificaram que a coloração do suco de cereja, entre consumidores de diferentes idades, teve efeito específico na aceitação, na qualidade e no sabor. Os consumidores, em sua grande maioria, preferem frutas com maior intensidade de coloração vermelha da epiderme, pois é associada a maiores teores de açúcares e a frutas saudáveis (Layne et al., 2002; Trevisan et al., 2006). Neste trabalho, obteve-se informação semelhante: a maioria dos consumidores (70\% do total) prefere pêssegos com epiderme amarelo-avermelhada. No entanto, os percentuais variaram de uma cidade para outra: Pelotas (59\%), Sant'Ana do Livramento (87\%) e Porto Alegre (65\%) (Figura 2B).

O tamanho das frutas é outro atributo de qualidade importante para os consumidores. Mas as frequências variaram entre as cidades e entre os sexos nas cidades de Porto Alegre e Sant'Ana do Livramento (Figura 2C). Em Pelotas (67\% do total) e Porto Alegre (81\% das mulheres e 66\% dos homens) a maioria dos consumidores preferiu fruta de tamanho médio, enquanto em Sant'Ana do Livramento o tamanho grande foi o preferido (51\% das mulheres e 71\% dos homens) (Figura 2C).

Pêssegos com polpa amarela a amarela intensa foi a cor preferida na cidade de Pelotas e Sant'Ana do Livramento, para ambos os sexos (Figura 2D). Em Pelotas isso pode ser explicado, principalmente, pelo fato de mais de $95 \%$ da produção de pêssegos de polpa amarela ser destinada à indústria, estando, portanto, mais disponível ao consumidor. Consumidores do sexo feminino de Porto Alegre (48\%) preferem frutas de polpa branca, que é a característica da produção daquela região (Figura 2E).

O sabor, a doçura e a suculência são atributos que o consumidor não consegue avaliar no momento da compra, e que, na maioria das vezes, são determinantes na recompra. Os atributos sabor e doçura não variaram entre os sexos e as cidades. Babicz-Zielinska (1999) observou que, dentre 28 diferentes tipos de frutas, os consumidores do norte da Polônia, escolheram o pêssego como a melhor fruta, em consequência do seu gosto doce.

A firmeza de polpa está diretamente associada à manutenção da integridade e do produto, tendo os consumidores de Pelotas (50\%) e Porto Alegre (54\%) preferência pelas tenras, enquanto a maioria dos consumidores de Sant' Ana do Livramento (79\%) preferiram frutas macias (Figura 2F).

No que se refere ao atributo suculência da fruta, $52 \%$ do total de consumidores do sexo masculino e a maioria dos consumidores do sexo feminino (52\% em Pelotas e 54\% em Sant'Ana do Livramento) preferiram frutas com suculência regular. Mas em Porto Alegre, as mulheres preferiram frutas com suculência regular e muito suculentas, com a mesma frequência (49\%) (Figura 2G). O mesmo foi destacado por consumidores de peras na Nova Zelândia, que além da importância da aparência da fruta e do sabor doce, preferem frutas suculenta (Jaeger et al., 2003). 
TABELA 1 - Testes de qui-quadrado $\left(\chi^{2}\right)$ para a associação entre o atributo cidade do consumidor e os demais atributos estudados, para cada sexo. Pelotas-RS, 2007.

\begin{tabular}{clccc}
\hline Atributos associados a cidade & \multicolumn{1}{c}{ Sexo } & GL & $\chi^{2}$ & Prob. $>\chi^{2}$ \\
\hline \multirow{2}{*}{ Faixa etária } & Masculino & 8 & 17,62 & 0,0243 \\
& Feminino & 8 & 16,43 & 0,0366 \\
Escolaridade & Masculino & 12 & 49,73 & $<0,0001$ \\
& Feminino & 12 & 75,49 & $<0,0001$ \\
Profissão & Masculino & 10 & 30,43 & 0,0007 \\
& Feminino & 10 & 13,81 & 0,1818 \\
Motivo da compra & Masculino & 6 & 12,52 & 0,0513 \\
& Feminino & 4 & 17,21 & 0,0018 \\
Local da compra & Masculino & 6 & 33,98 & $<0,0001$ \\
& Feminino & 6 & 25,59 & 0,0003 \\
Frequência do consumo & Masculino & 8 & 36,68 & $<0,0001$ \\
& Feminino & 6 & 22,35 & 0,0010 \\
Identificação da cultivar & Masculino & 2 & 24,37 & $<0,0001$ \\
& Feminino & 2 & 9,06 & 0,0108 \\
Firmeza & Masculino & 6 & 44,15 & $<0,0001$ \\
& Feminino & 6 & 67,08 & $<0,0001$ \\
Suculência & Masculino & 4 & 7,88 & 0,0961 \\
& Feminino & 6 & 13,04 & 0,0424 \\
Tamanho da fruta & Masculino & 4 & 22,24 & 0,0002 \\
& Feminino & 4 & 27,71 & $<0,0001$ \\
Atributo mais importante & Masculino & 6 & 32,09 & $<0,0001$ \\
& Feminino & 12 & 37,02 & 0,0002 \\
\hline \multirow{2}{*}{ Cor da polpa } & Feminino & 6 & 46,70 & $<0,0001$ \\
& Masculino & 8 & 23,50 & 0,0028 \\
& Feminino & 8 & 31,46 & 0,0001 \\
& Masculino & 12 & 28,68 & 0,0044 \\
& & & & \\
& & &
\end{tabular}

TABELA 2- Testes de qui-quadrado $\left(\chi^{2}\right)$ para a associação entre o atributo sexo do consumidor e os demais atributos estudados, para cada cidade. Pelotas-RS, 2007.

\begin{tabular}{clccc}
\hline Atributos associados a sexo & Cidade & GL & $\chi^{2}$ & Prob. $>\chi^{2}$ \\
\hline \multirow{2}{*}{ Profissão } & Livramento & 6 & 30,02 & $<0,0001$ \\
& Pelotas & 5 & 41,68 & $<0,0001$ \\
& Porto Alegre & 4 & 8,05 & 0,0896 \\
Motivo da compra & Livramento & 2 & 10,13 & 0,0063 \\
& Pelotas & 3 & 2,71 & 0,4378 \\
& Porto Alegre & 3 & 8,00 & 0,0460 \\
Local da compra & Livramento & 3 & 3,78 & 0,2867 \\
& Pelotas & 3 & 11,63 & 0,0088 \\
& Porto Alegre & 3 & 15,81 & 0,0012 \\
Frequência do consumo & Livramento & 3 & 1,31 & 0,7274 \\
& Pelotas & 3 & 3,39 & 0,3358 \\
& Porto Alegre & 4 & 16,34 & 0,0026 \\
Identificação da cultivar & Livramento & 1 & 6,59 & 0,0102 \\
& Pelotas & 1 & 21,02 & $<0,0001$ \\
& Porto Alegre & 1 & 3,32 & 0,0683 \\
Cor da polpa & Livramento & 3 & 4,36 & 0,2248 \\
& Pelotas & 3 & 4,03 & 0,2580 \\
& Porto Alegre & 3 & 11,38 & 0,0098 \\
Tamanho da fruta & Livramento & 2 & 7,01 & 0,0300 \\
& Pelotas & 2 & 0,36 & 0,8369 \\
& Porto Alegre & 1 & 3,86 & 0,0496 \\
\hline
\end{tabular}


(A)

Motivo da compra

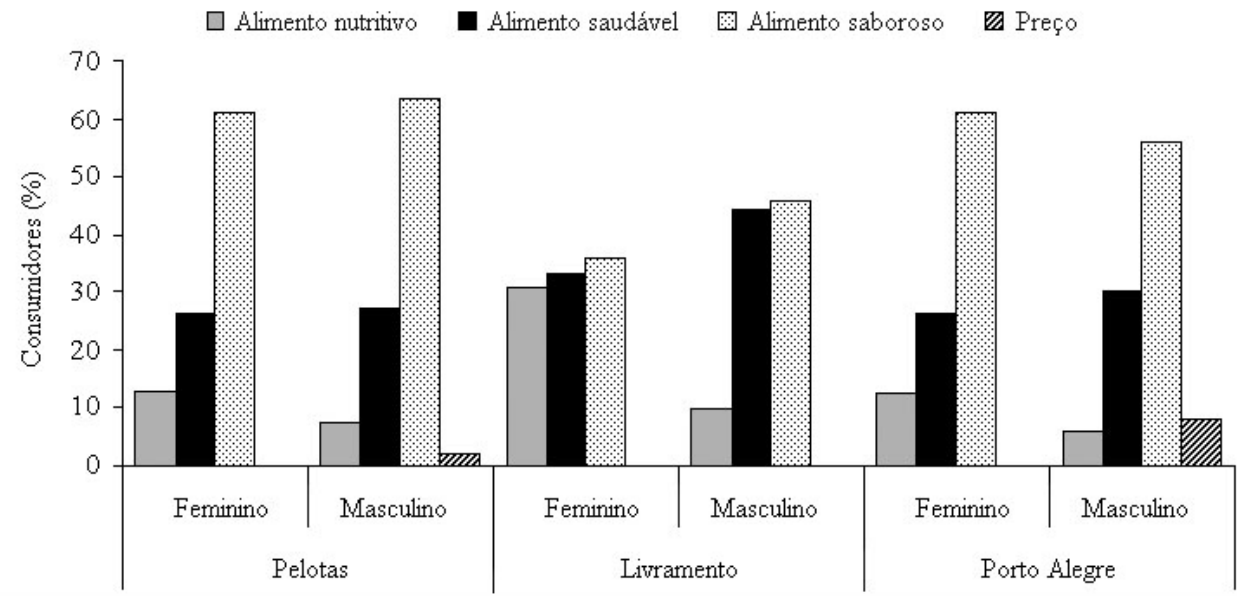

(B)

Local de compra

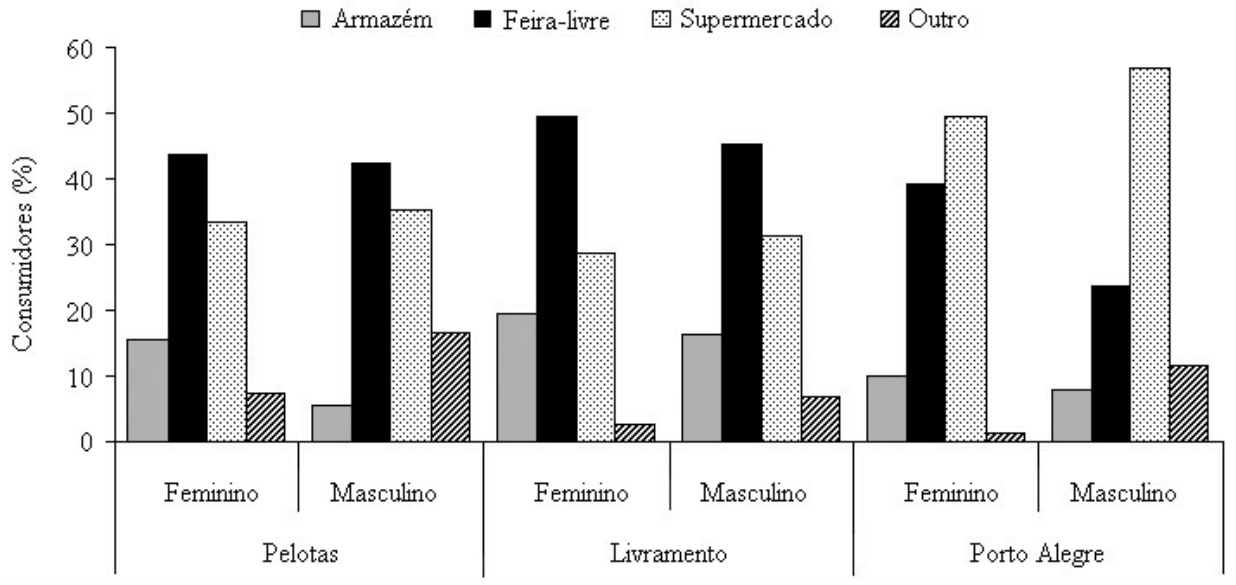

(C)

Frequência de consumo

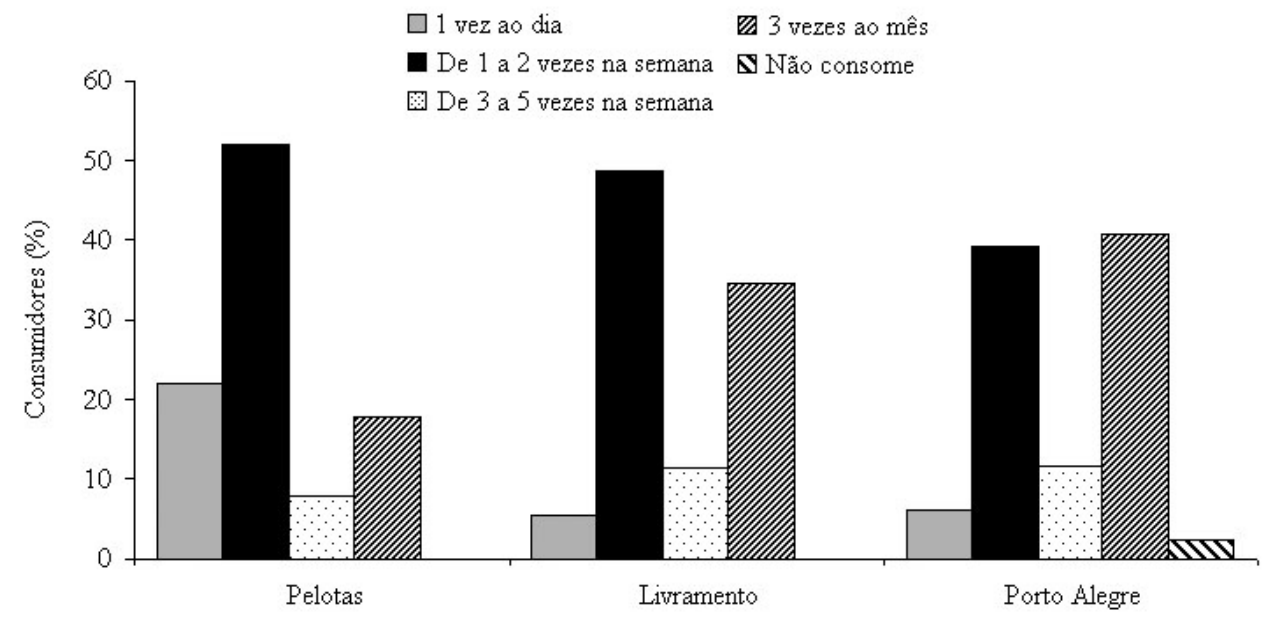

continua 
continuação

(D) Frequência de consumo

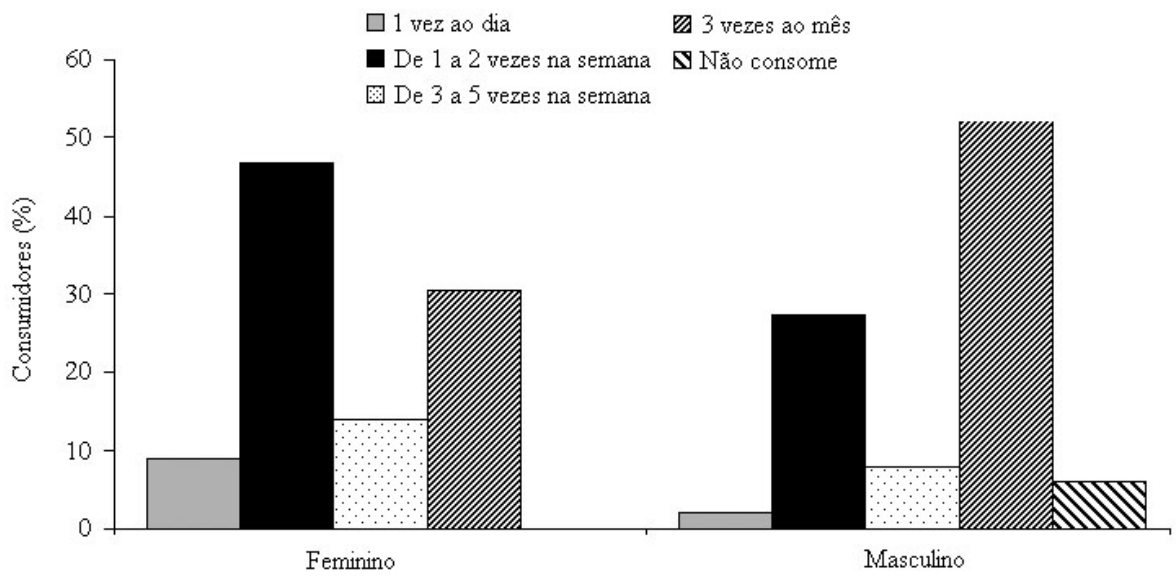

(E)

Conhecimento das cultivares

$$
\square \operatorname{Sim} \square \text { Não }
$$

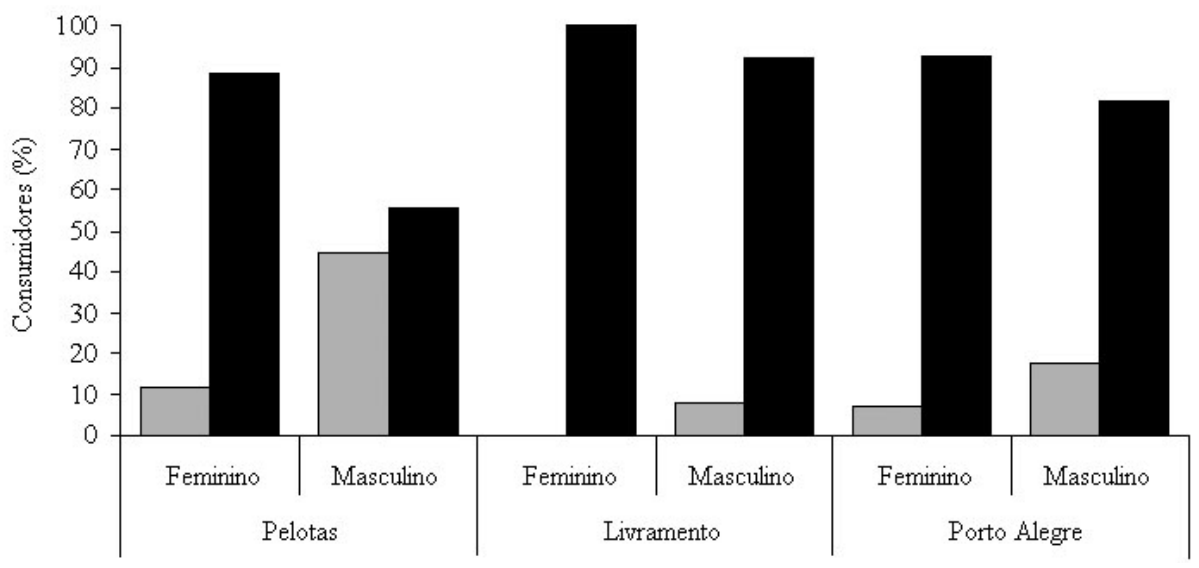

FIGURA 1 - Distribuição dos consumidores de pêssego para os atributos motivo da compra (A), local da compra (B), frequência de consumo por cidade (C), por sexo do consumidor (D), conhecimento das cultivares (E). Pelotas-RS, 2007 
(A) Atributo de qualidade

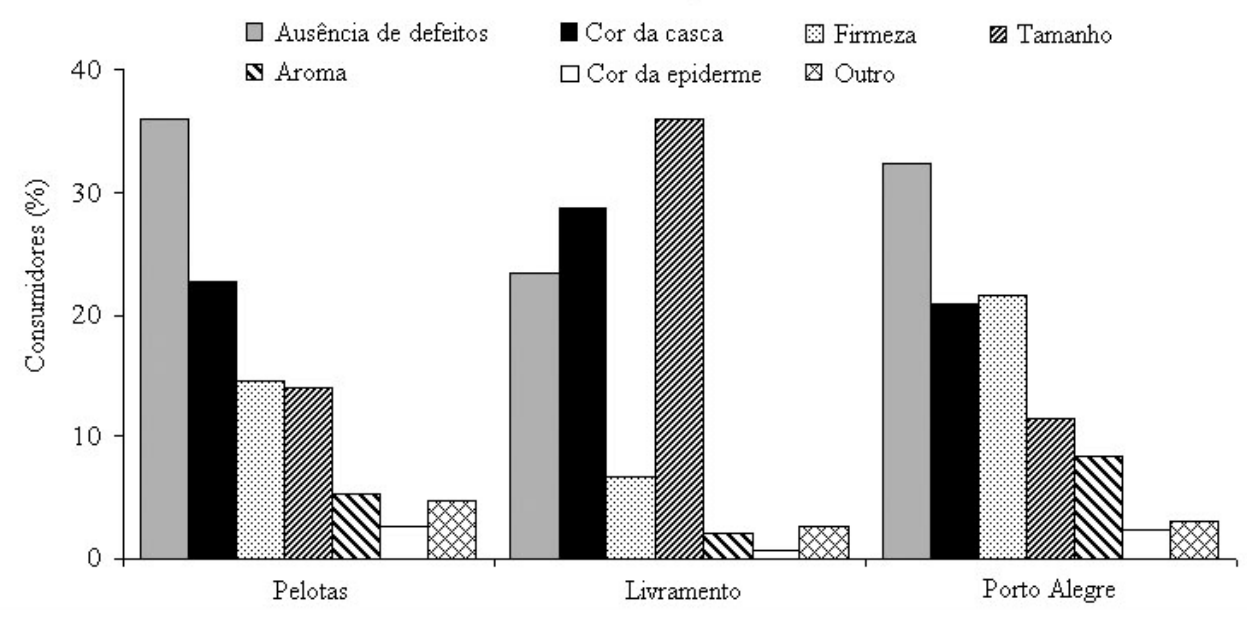

(B) Cor da epiderme
$\square$ Amarelo-avermelhado
- Amarelo
Vormelho
Laranja
\$ Amarelo-esverdeado

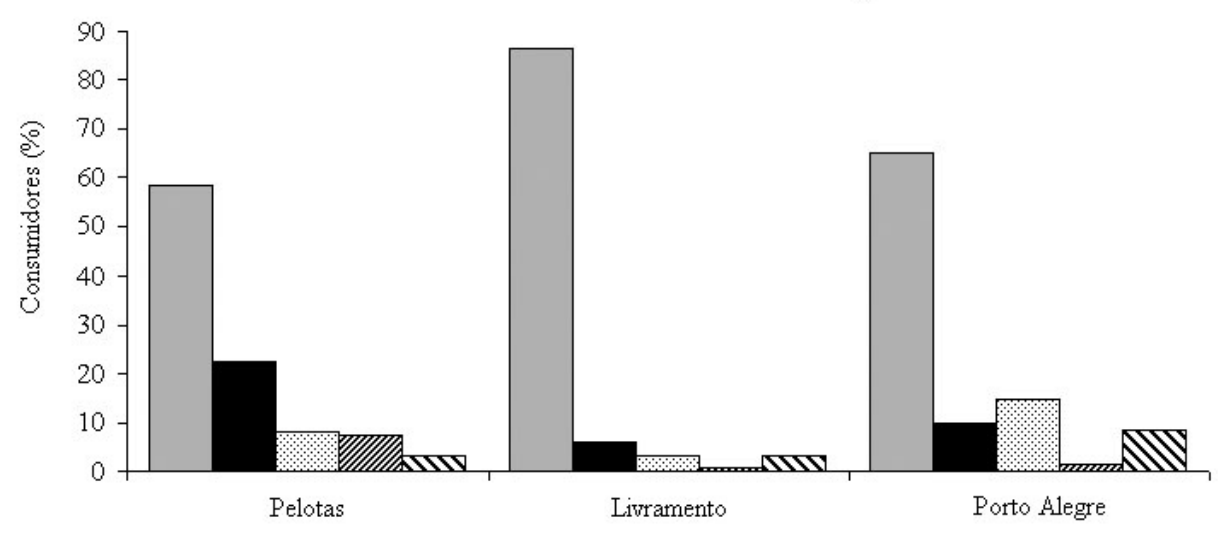

(C) Tamanho da fruta

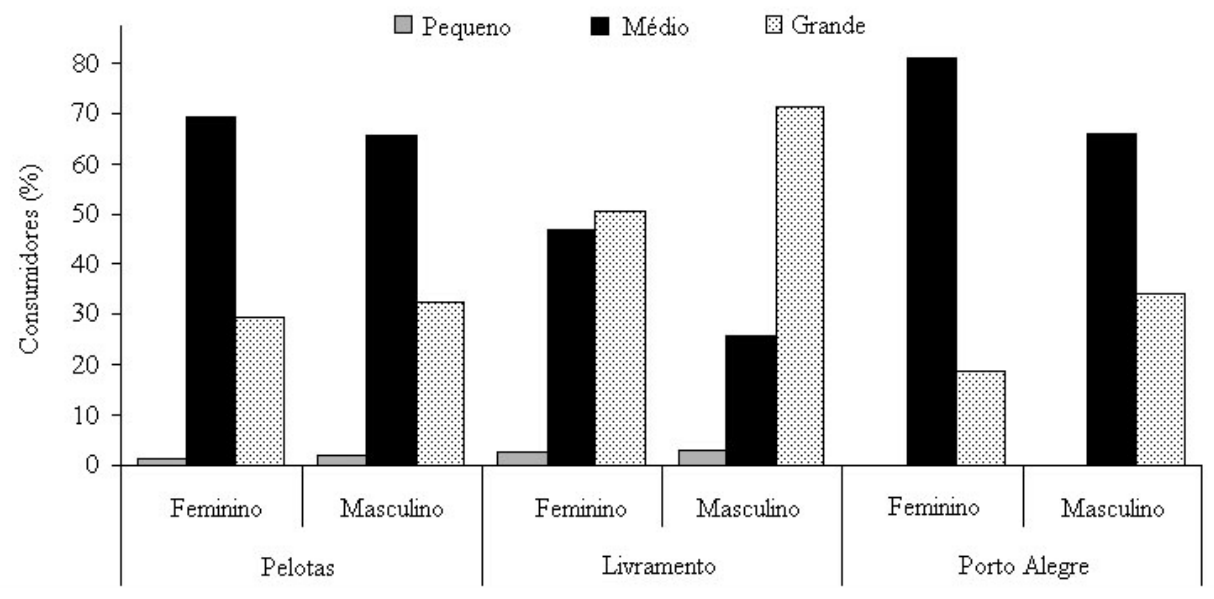


continuação

(D)

Cor da polpa

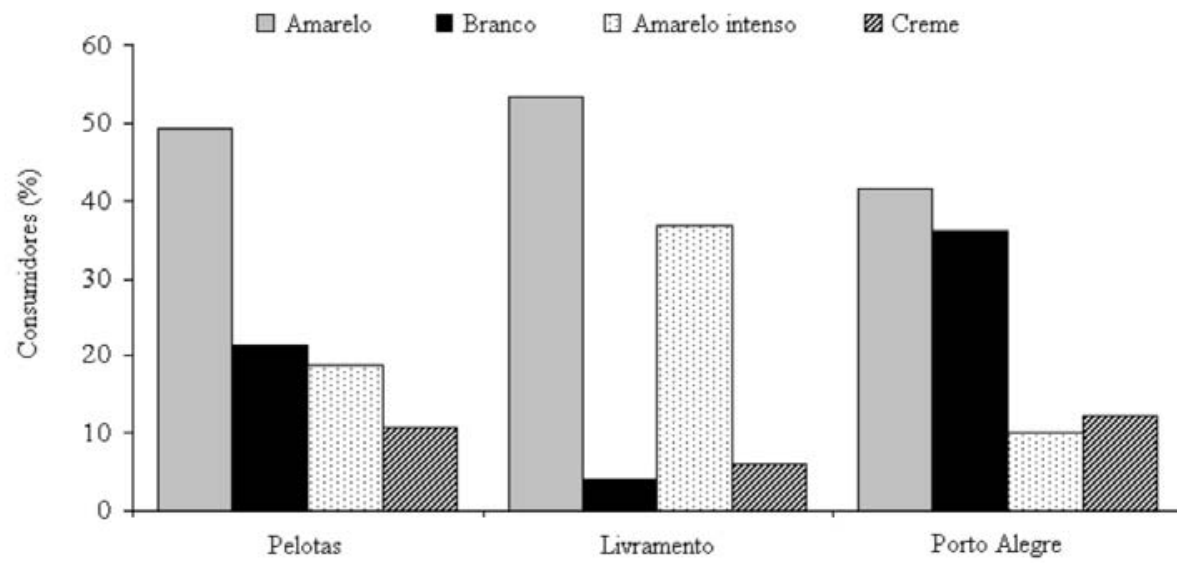

(E)

Cor da polpa

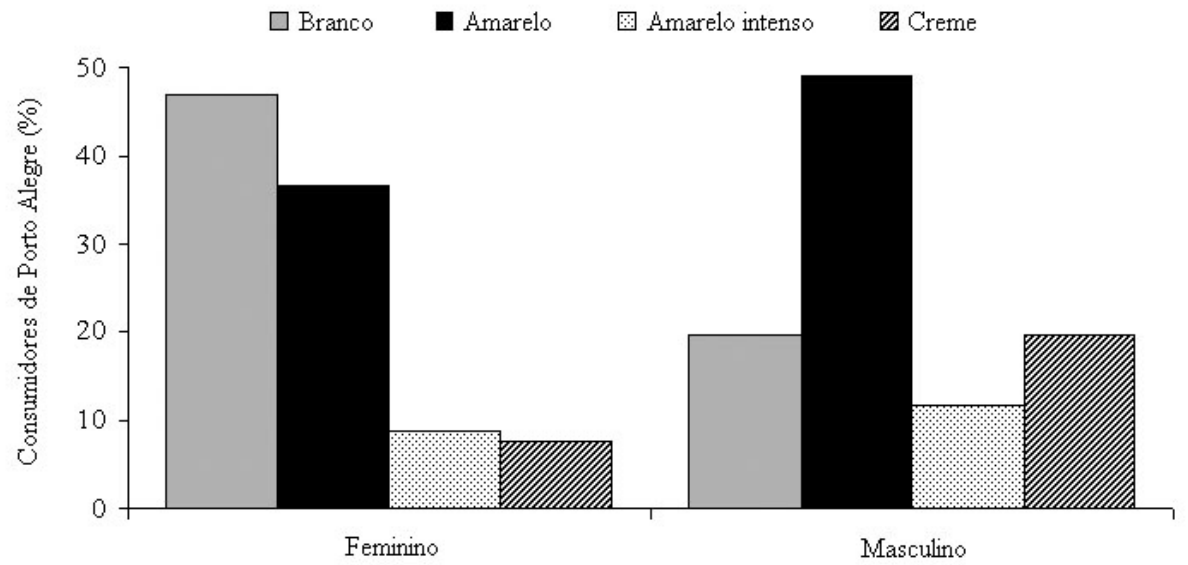

(F)

Firmeza

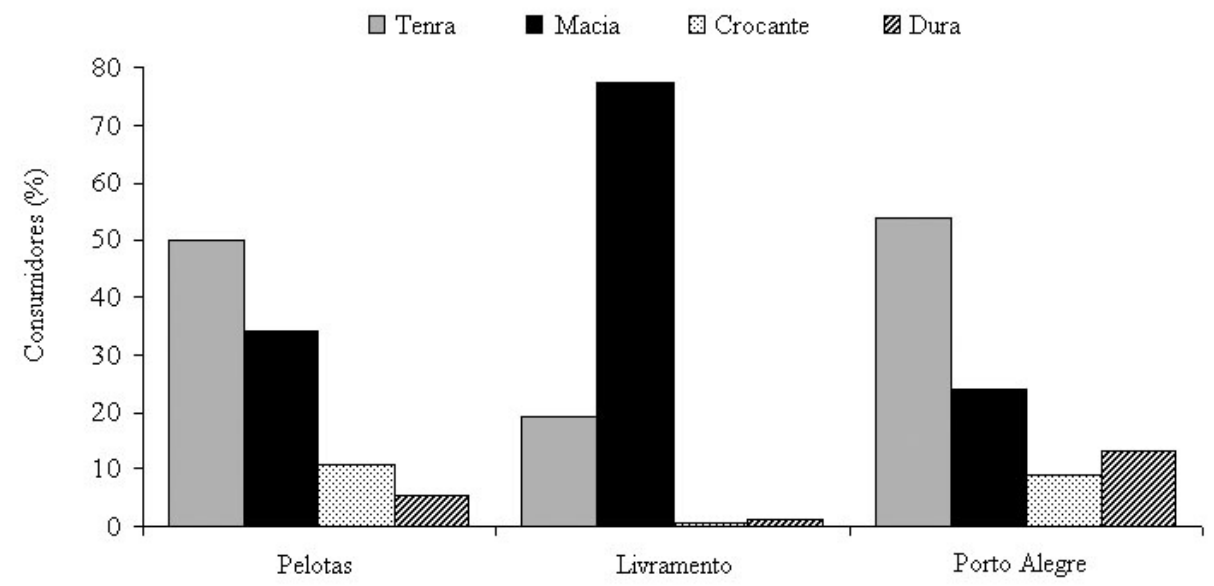

continua 
continuação

(G)

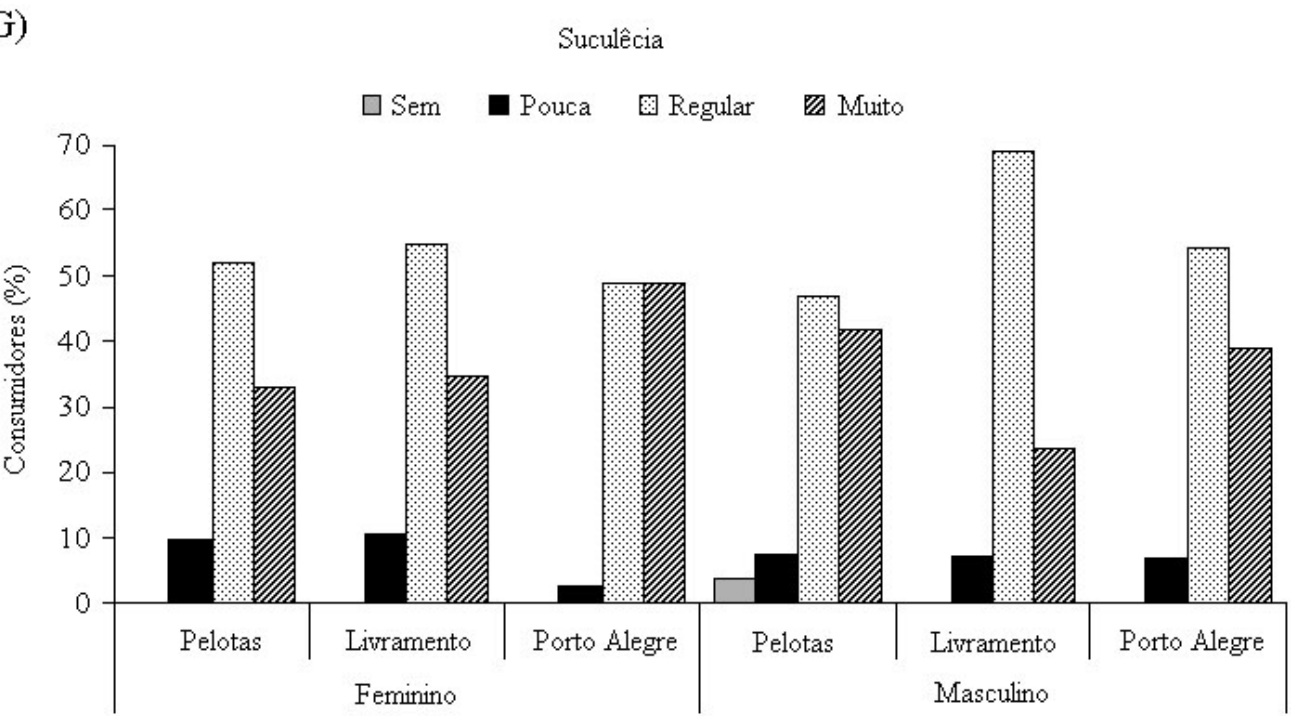

FIGURA 2 - Distribuição dos consumidores de pêssego para os atributos mais importante no momento da compra (A), cor da epiderme (B), tamanho da fruta (C), cor da polpa, por cidade (D), e cor da polpa por sexo em Porto Alegre (E), firmeza da polpa (F) e suculência (G). Pelotas-RS. 2007.

\section{CONCLUSÕES}

1-Os consumidores de Pelotas e Sant'Ana do Livramento preferem pêssegos de polpa amarela e compram principalmente em feira livre. Em Porto Alegre, o maior consumo é pêssegos de polpa branca, adquiridos no supermercado.

2-Frutas sem defeito é o atributo mais importante no momento da escolha pelos consumidores de Pelotas e Porto Alegre, e Sant' Ana do Livramento é o tamanho da fruta.

3-A grande maioria dos consumidores das cidades pesquisadas não conhece as cultivares pelo nome, consomem a fruta uma a duas vezes na semana e têm preferência por frutas de tamanho médio a grande, com coloração da epiderme amarelo-avermelhada, sendo o sabor da fruta o principal motivo da compra, que deverá ser de doce a doce-ácido e de regular a muito suculento.

\section{AGRADECIMENTOS}

À FAPERGS (processo 04/0579-9) e ao CNPq (processo 304172/03-0), pelo suporte financeiro.

\section{REFERÊNCIAS}

BABICZ-ZIELINSKA, E. Food preferences among the Polish young adults. Food quality and preferences, London, n. 1, p.139-145, 1999.

BRUMFIELD, R.G.; ADELAJA, A.O.; LININGER, K. Consumer tastes, preferences, and behavior in purchasing fresh tomatoes. Journal American Society Horticultural Science, Alexandria, v.118, n.3, p.433-438, 1993.

CAMPBELL, B.L.; NELSON, G.R.; EBEL, R.C.; DOZIER, W.A.; ADRIAN, J.A.; HOCKEMA, B.R. Fruit quality characteristics that affect sumer preferences for Satsuma Mandarins. HortScience, Alexandria. v. 39, n.7, p.164-1669, 2004.

CASTELLARI, L.; MALAVOLTI, A.; COLOMBO, R.; RONDINELLI, G.P. L’impiego dei panel test nella valutazione qualitativa di alcune nettarine Emiliano-romagnole. Rivista Frutticoltura e di Ortofloricoltura, Bologna, n.7, p.60-63, 2006.

CRISOSTO, C.H.; CROSOSTO, G.M.; METHENEY, P. Consumer acceptance of Brooks and Bing cherries is mainly dependent on fruit SSC and visual skin color. Postharvest Biology and Technology, Amsterdan, v. 28, p.159-/167, 2003. 
GONÇALVES, J. R. A. O consumidor de frutas frescas da cidade de Lavras-MG. 1998. 122f. Dissertação (Mestrado em Administração Rural) Universidade Federal de Lavras, Lavras, 1998.

HOOLEY, G.J.; SUNDERS, J.A.; PIERCY, N.F. Estratégia de marketing e posicionamento competitivo. 2. ed. São Paulo: Prientice Hall, 2001. 423p.

JAEGER, S.R.; LUND, C.M.; LAU, K.; HARKER, F.R. In Search of the "Ideal” Pear (pyrus spp.): Results of a Multidisciplinary Exploration. Journal of Food Science. New Zealand, v. 68, n.3, p. 11081117, 2003.

IMRAM, N. The role of visual cues in consumer perception and acceptanace of a food product. Nutrition \& Food Science, Texas, n.5, p.224-228, 1999.

LAYNE, D. R.; JIANG, Z.; RUSHING, J. W. The influense of reflective film and tetain on red skin coloration and maturity of gala apples. HortTechnology, Alexandria, v.12, n.4, p.640-644, 2002.

LÓPES, J.L.; VALERO, M. M.; RUIZ-ALTISENT, M.; BARREIRO, P. Harinosidade en manzana y melocotón:sondeo a los consimidores de Madrid. Revista Fruticultura Profesional, Madrid, n.98, p.56-65, 1998.

MACCHI, E. Stabilizzati i consumoi di pesche, in lieve crescita quelli di nettarine. Rivista di Frutticoltura e di Ortofloricoltura, Bologna, n.3, p.4-5, 2007.

MARODIN, G. A. B.; SARTORI, I.A. Situação das frutas de caroço no Brasil e no mundo. IN: SIMPÓSIO INTERNACIONAL DE FRUTAS DE CAROÇO: PÊSSEGOS, NECTARINAS E AMEIXAS, 2000, Porto Alegre. Anais... Porto Alegre: Universidade Federal do Rio Grande do Sul, 2000. p. 7-16.
MATSUURA, F.C.A.U.; COSTA, J.I.P.; FOLEGATTI, M.I.S. Marketing de banana: Preferências do consumidor quanto aos atributos de qualidade dos frutos. Revista Brasileira de Fruticultura. Jaboticabal, v. 26, n. 1, p. 48-52, 2004.

MATTAR, F.N. Pesquisa de marketing: metodologia, planejamento. 5.ed. São Paulo: Atlas, 1999, v.1. 339 p.

PHILIPSEN, D.H.; CLYDESDALE, F.M.; GRIFFIN, R.W.; STERN, P. Consumer age affects response to sensory characteristics of a cherry flavored beverage. Journal of Food Science, London, v. 60, n.2, p.364-368, 1995.

PIO R.; RAMOS, J.D. Características do consumidor de frutas nos municípios de Lavras e Perdões-MG. Unimar Ciências, Marília, v.11, n.2, p.103-108, 2002.

SAS INSTITUTE . SAS/STAT user's guide: Version 6. $4^{\text {th }}$ ed. Cary, 1989. 846p.

TORALLES, R.P.; MALGARIM, M.B.; VENDRUSCOLO, J.L.; CANTILLANO, R.F.F.; TREPTOW, R.O. Um estudo para compreender a preferência e aceitação de consumidores de purês de pêssegos brasileiros. Revista Brasileira de Fruticultura, Jaboticabal, v. 28, n. 3, p. 397-401, 2006.

TREVISAN, R.; HERTER, F.G.; COUTINHO, E.F.; EMERSON DIAS GONÇALVES, E.D.; SILVEIRA, C.A.P.; FREIRE, C.J.S. Uso de poda verde, plásticos refletivos, antitranspirante e potássio na produção de pêssegos. Pesquisa Agropecuária Brasileira, Brasília, v.41, n.10, p.1485-1490, 2006.

WILKINS, J.L.; BOWDISH, E.; SOBAL, J. Consumer perceptions of seasonal and local foods: A study in a US community. Ecology of Food and Nutrition, New York, v.41, n.5, p.415-439, 2002. 